\title{
Prevalence of Traditional Herbs and Supplements Use Among Hypertensive Patients in Om Elamad Health Center
}

\author{
Dua Al-Hadid', Raad Jaber Musa ${ }^{2, *}$, Ahmad Al-Talhuni ${ }^{3}$, Jamal Alyoussef Alkrad ${ }^{4}$
}

Dua Al-Hadid', Raad Jaber Musa ${ }^{2, *}$, Ahmad Al-Talhuni ${ }^{3}$, Jamal Alyoussef Alkrad ${ }^{4}$

'Ministry of Health, Amman, JORDAN. 2Professor of Pathology, Faculty of Pharmacy, Isra University, PO Box 22 and 23, Amman, JORDAN.

${ }^{3}$ Assitant Professor, Faculty of Pharmacy, Isra University, PO Box 22 and 23, Amman, JORDAN.

${ }^{4}$ Associate Professor, Faculty of Pharmacy, Isra University, PO Box 22 and 23, Amman, JORDAN.

\section{Correspondence}

\section{Raad Jaber Musa}

Professor of Pathology, Faculty of

Pharmacy, Isra University, PO Box 22 and 23, Amman, JORDAN.

E-mail: raad.alani@iu.edu.jo

History

- Submission Date: 04-07-2020;

- Review completed: 18-08-2020;

- Accepted Date: 20-08-2020

DOI : 10.5530/pj.2020.12.221

Article Available online

http://www.phcogj.com/v12/i6s

\section{Copyright}

(C) 2020 Phcogj.Com. This is an openaccess article distributed under the terms of the Creative Commons Attribution 4.0 International license.

\section{ABSTRACT}

Background: In recent years, hypertension has developed into a global health concern as the number of deaths from it has been on the increase across the world. Health provision in Jordan like other developing nations is poor compared to countries like the United Kingdom (UK) and US. However, concurrent use of conventional medication and the supplements and traditional herbs can impact on the treatment of hypertension. In this regards, it was significant to conduct this study to find out the prevalence of supplements and traditional herbs usage among hypertensive patients in Jordan so as to understand the associated factors and create awareness on the magnitude so that appropriate advice can be given to patients and thus improve health of populations. Material and Methods: The study employed a cross-sectional study design in undertaking the research. A total of 208 hypertension patients aged 16 years and above were used as the sample. Purposive and convenient sampling was applied in the selection of the Om elamad health centre in Jordan because it has a population of the catchment Centre. Data analysis was carried out using various techniques SPSS version21and excel. Results: The key findings of the study were as follows: Hypertension was prevalent among the elderly, herbs had no effect on the blood pressure, conventional drugs were more potent in comparison to herbs and/or supplements. Combining antihypertensive drugs and herbs was found to be potent than taking antihypertensive drugs only (P-value $=0.0050)$ in $S B P$, and (P-value $=0.0001$ ) in DPB. Influences on herbs use came from the patients' families/relatives as they were found to be the most knowledgeable sources of medicinal herbs. Conclusion: From the study, it was deduced that the use of herbal medicines and supplements as well as antihypertensive drugs was prevalent among hypertensive patients in Jordan. Over half of the patients involved in this study were taking herbs to treat their blood pressure diseases (51. $4 \%)$. It was also deduced that a combined usage of herbal medicine and supplements with antihypertensive drugs was far more potent than using antihypertensive drugs only.

Key words: Traditional Herbs, Supplements, Hypertensive, Om Elamad Health Center.

\section{INTRODUCTION}

Hypertension has become a health concern worldwide in the recent two decades since it has become the leading risk factor in terms of disease burden globally. ${ }^{1}$ According to the latest World Health Organization, data published in May 2014 Hypertension Deaths in Jordan reached 1,117 or $4.85 \%$ of total deaths. ${ }^{2}$ Control of blood pressure is suboptimal and only about $40 \%$ of patients suffering from hypertension manage to reach the target blood pressure level of $120 / 80 \mathrm{~mm} \mathrm{Hg}$ and below.

Hypertension defined as diastolic BP above $80 \mathrm{~mm}$ $\mathrm{Hg}$ or systolic BP above $120 \mathrm{~mm} \mathrm{Hg.}{ }^{3}$ Treatment normally involve the use of antihypertensive medications, however, almost half of people diagnosed with hypertension do not seek right medication to control it. Lowering BP is important measure in preventing health complications of hypertension like cardiovascular conditions. Lowering BP to below $120 \mathrm{mmHg}$ in the case of systolic BP reduces the likelihood of death and development of cardiovascular conditions.

Prevalence of supplements and traditional herbs in treatment of hypertension is high in both developed and developing countries alike. About $65 \%$ to $80 \%$ of global adult population have used supplements and traditional herbs as a primary health intervention at some point in their lives. ${ }^{4-17}$ According to the WHO report in $2008,75 \%$ of the world's populations are using herbs for the management of basic healthcare needs, with over 60 billion American dollars invested in the trade market of herbal medicines. ${ }^{2}$ In Jordan, use of herbal medicine is reported to be high, hence investigating the use and safety of herbal medicine has become a national priority. ${ }^{6}$ Limited information exist on extent of usage among patients in Jordan particular in Om elamad area despite the potential side effects associated with nonconventional medications.

However, there is no study that has been published about prevalence of supplements and traditional herbs usage among hypertensive patients attending Om Elamad health centre and surrounding regions hence this study will close this gap in literature. The aim of this study is to determine prevalence and utilization of supplements and traditional herbs among patients with hypertension attending Om elamad health centre, to evaluate the control of blood pressure (systolic and diastolic) in hypertensive patients that take both herbal medicines and

Cite this article: Al-Hadid D, Musa RJ, Al-Talhuni A, Alkrad JA. Prevalence of Traditional Herbs and Supplements Use Among Hypertensive Patients in Om Elamad Health Center. Pharmacogn J. 2020;12(6)Suppl:1612-22. 
conventional medicines and patients taking conventional medicines alone,to assess the safety and side effects associated with utilization of supplements and traditional herbs among hypertensive patients and to determine the socioeconomic and demographic characteristics of hypertensive patients attending Om elamad health center.

\section{SUBJECTS AND METHODS}

A total of 200 Hypertensive patients in Om elamad health Centre, in the period from October,2018-June,2019. All of whom diagnosed with hypertension for at least 1 year, both genders, and not too ill to communicate with the researcher.

The hypertensive patients was divided into four groups

- Group 1: patients taking drug only.

- Group 2: patients taking herbs \&lor supplements only.

- Group 3: patients taking drug and herbs and supplements.

- Group 4: patients taking drug and herbs.

Study tool

A pretested and validated questionnaire used for data collection.

The questionnaire is attached at the appendix page no.19

\section{Method}

Cross sectional study design was adopted by the study in order to examine the prevalence of utilization of supplements and traditional herbs by hypertensive patients in Jordan. Each of the samples studied provided comprehensive and cross-sectional information regarding their behaviour of using medications for management and treatment of hypertension. Research approach used in this study was mainly quantitative approach since the data was gathered using quantitative methods.

\section{Sampling}

Sample targeted in this study included patients attending Om elamad health centre in Jordan. The requirement was that the patient must be an adult and have been confirmed to have hypertension.

Purposive and convenience sampling was used to select Om elamad health centre in Jordan. Om elamad health centre was selected because this health centre provides conventional treatment to hypertensive patients, moreover, people in the region tend to rely on supplement and traditional herbs. A total of 200 hypertensive patients were studied from Om elamad health centre after giving consent to participate out of which 208 questionnaires were found to be complete and answered consistently.

\section{Inclusion criteria}

Diagnosed hypertensive patients on conventional medication, managed at om elamad health center outpatient for at least 6 months, should be 16 years and above, and willing to participate in the study.

\section{Data collection \& statistical analysis}

Data collection methods involved two main approaches including administration of questionnaires and interview technique which enabled the study to obtain primary data. In addition, questionnaire data can be analysed easily when coded with the aid of software SPSS version 21 . The questionnaire used in this study had three parts namely: Part A on individual patient characteristics including sociodemographic factors and patient history; Part B included questions that assessed efficacy of supplements and traditional herbs; and Part C contained observation checklist where readings on BP were taken and recoded against a given date .

\section{Ethics}

Consent was considered from the participants. Information obtained was kept confidential and the study subjects were kept anonymous

\section{RESULTS}

\section{Characteristics of the study sample}

The characteristics of study sample indicate that the percentage of male $(52.4 \%)$ representation is higher than that of female $(47.6 \%)$ representation. In terms of age, the highest percentage of the sample was aged 55-65 (33.2\%), 65\% (27.9\%) and the lowest age group (26-35) which amounted to $(2.4 \%)$.

In terms of educational level, we find that the highest proportion of the sample of the secondary education by $(41.3 \%)$, and in the second degree was the proportion of students with a bachelor's degree $(22.1 \%)$, then came the proportion of non-educated (21.6\%).

The results of the marital status indicate that the majority of the sample is married $(97.1 \%)$. The economic indicators indicate that the economic level of the sample is low by $(59.1 \%)$ of them are not working and (59.1\%) are less than 500 JD per month.

It is also noted that the highest percentage of the respondents are practicing sports $(68.7 \%)$, while the percentage of non-practicing sports $(31.3 \%)$.

The data of the tables $(2,3)$ indicate that the average weights of the study subjects reached (76.59) $\mathrm{kg}$ and standard deviation (12.09) kg, while the average length $(163.69) \mathrm{cm}$ and standard deviation $(7.70) \mathrm{cm}$. In terms of body mass index, it came with an average of (28.03) and a standard deviation (4.35). The results of the body mass also indicate that $(34.6 \%)$ of the study subjects are obese, $37.5 \%$ are overweight and only (27.9\%) have normal weight.

Table (4) shows the health conditions of the study subjects. It is noted that the hypertensive patient which suffer from diabetes is $(90.4 \%)$, (53.8\%) of kidney problems, While the percentage decreases to $(4.3 \%)$ with cardiovascular disease, and (2.9\%) with heart problems.

Table (5) shows that (61.5\%) of the subjects have a family history of hypertension. Only (38.5\%) have no family history with hypertension.

Table (6) shows the smoking status of the study sample. The percentage of smokers is $(43.3 \%)$. The percentage of passive smokers $(38.5 \%)$. In terms of the number of smoked cigarettes per day, the highest rate of smoking is between $20-29$ cigarettes (42.2\%). In the second category, the percentage of smokers who smoked between 10-19 cigarettes per day was $(26.7 \%)$.

Table (7) shows the lifestyle and changes in the diet of the study subjects. It is noted that (51.4\%) of the individuals work on reducing the salt. The percentage of those working on weight reduction is $(40.4 \%)$. While the proportion of exercise regularly (32.7\%).

The data in Table (8) show that the highest percentage of study subjects received drugs have high blood pressure (79.8\%). It is also noted that the most drugs taken by the patients was Bisoprolol fumarate by $(34.3 \%)$. Then in the second class came Atenolol by (15.1\%).

Table (9) shows that (51.4\%) of the study subjects take medicinal herbs to treat blood pressure.

It is clear from the data of Table (10) that the most medicinal herbs taken by the study members are garlic (36.5\%). In the second class came 
Table 1: Percentage Distribution of Study Sample Population by Social, Economic and Demographic Variables.

\begin{tabular}{|c|c|c|c|}
\hline Variable & Variable classes & Frequency & Percent \\
\hline \multirow{3}{*}{$\operatorname{sex}$} & $\mathrm{M}$ & 109 & 52.4 \\
\hline & $\mathrm{F}$ & 99 & 47.6 \\
\hline & Total & 208 & 100.0 \\
\hline \multirow{6}{*}{ age } & $26-35$ & 5 & 2.4 \\
\hline & $36-45$ & 24 & 11.5 \\
\hline & $46-55$ & 52 & 25.0 \\
\hline & $55-65$ & 69 & 33.2 \\
\hline & above 65 & 58 & 27.9 \\
\hline & Total & 208 & 100.0 \\
\hline \multirow{5}{*}{ level of education } & Primary school & 14 & 6.7 \\
\hline & high school & 86 & 41.3 \\
\hline & diploma & 17 & 8.2 \\
\hline & University degree & 46 & 22.1 \\
\hline & have not been to school & 45 & 21.6 \\
\hline \multirow{8}{*}{ residential address } & Total & 208 & 100.0 \\
\hline & al khadra & 10 & 4.8 \\
\hline & al-samik & 25 & 12.0 \\
\hline & al-zaitonah & 25 & 12.0 \\
\hline & al-zaitre & 2 & 1.0 \\
\hline & manja & 25 & 12.0 \\
\hline & om al amad & 107 & 51.4 \\
\hline & om-romana & 14 & 6.7 \\
\hline \multirow{4}{*}{ marital status } & Total & 208 & 100.0 \\
\hline & married & 202 & 97.1 \\
\hline & other & 6 & 2.9 \\
\hline & Total & 208 & 100.0 \\
\hline \multirow{3}{*}{ employed } & yes & 85 & 40.9 \\
\hline & no & 123 & 59.1 \\
\hline & Total & 208 & 100.0 \\
\hline \multirow{3}{*}{ Income } & $<500 \mathrm{JD}$ & 123 & 59.1 \\
\hline & 500-1000 JD & 85 & 40.9 \\
\hline & Total & 208 & 100.0 \\
\hline \multirow{5}{*}{ exercise } & Daily & 29 & 13.9 \\
\hline & often & 51 & 24.5 \\
\hline & sometime & 63 & 30.3 \\
\hline & Never & 65 & 31.3 \\
\hline & Total & 208 & 100.0 \\
\hline
\end{tabular}

Table 2: Mean and Standard deviation for Weight, Height and BMI Variables.

\begin{tabular}{ccc}
\hline Variable & Mean & Standard deviation \\
\hline Weight & 76.59 & 12.09 \\
Height & 163.69 & 7.70 \\
BMI & 28.03 & 4.35 \\
\hline
\end{tabular}

Table 3: Percentage Distribution of Study Sample Population by BMI.

\begin{tabular}{cccc}
\hline Variable & Variable classes & Frequency & Percent \\
\hline \multirow{2}{*}{ BMI } & normal weight & 58 & 27.9 \\
& overweight & 78 & 37.5 \\
& obesity & 72 & 34.6 \\
& Total & 208 & 100.0
\end{tabular}


Table 4: Percentage Distribution of Study Sample Population by Medical conditions.

\begin{tabular}{|c|c|c|c|c|c|c|}
\hline \multirow{2}{*}{ Medical conditions } & \multicolumn{2}{|c|}{ Yes } & \multicolumn{2}{|c|}{ No } & \multicolumn{2}{|c|}{ No answer } \\
\hline & Frequency & Percent & Frequency & Percent & Frequency & Percent \\
\hline Diabetes & 188 & 90.4 & 20 & 9.6 & 0 & 0.0 \\
\hline Heart problem & 6 & 2.9 & 200 & 96.2 & 2 & 1.0 \\
\hline Kidney disease high & 112 & 53.8 & 94 & 45.2 & 2 & 1.0 \\
\hline Blood pressure & 208 & 100 & 0 & 0 & 0 & 0.0 \\
\hline Vascular disease & 9 & 4.3 & 197 & 94.7 & 2 & 1.0 \\
\hline Strokes & 0 & 0.0 & 206 & 99.0 & 2 & 1.0 \\
\hline
\end{tabular}

Table 5: Percentage Distribution of Study Sample Population by family history of hypertension.

\begin{tabular}{ccc}
\hline Family history of hypertension & Frequency & Percent \\
\hline Yes & 128 & 61.5 \\
No & 80 & 38.5 \\
Total & 208 & 100.0 \\
\hline
\end{tabular}

Table 6: Percentage Distribution of Study Sample Population by smoking status.

\begin{tabular}{|c|c|c|c|}
\hline Variable & Variable classes & Frequency & Percent \\
\hline \multirow{5}{*}{ smoking status } & smoker & 90 & 43.3 \\
\hline & passive smoker & 80 & 38.5 \\
\hline & ex-smoker & 14 & 6.7 \\
\hline & not smoker & 24 & 11.5 \\
\hline & Total & 208 & 100.0 \\
\hline \multirow{5}{*}{ Number of cigarettes per day } & 9 or less & 2 & 2.2 \\
\hline & $10-19$ & 24 & 26.7 \\
\hline & $20-29$ & 38 & 42.2 \\
\hline & 30 or more & 26 & 28.9 \\
\hline & Total & 90 & 100.0 \\
\hline
\end{tabular}

Table 7: Percentage Distribution of Study Sample Population by Life Style and Diet changes.

\begin{tabular}{ccccc}
\hline \multirow{2}{*}{$\begin{array}{c}\text { Lifestyle and Diet } \\
\text { changes }\end{array}$} & Frequency & Percent & Frequency & No \\
\cline { 2 - 5 } & 107 & 51.4 & 101 & 48.6 \\
Salt reduction & 84 & 40.4 & 124 & 59.6 \\
Weight loss & 69 & 32.7 & 140 & 67.3 \\
Regular exercise & & & & Percent \\
\hline
\end{tabular}

Table 8: Percentage Distribution of Study Sample Population taking drug for hypertension.

\begin{tabular}{|c|c|c|c|}
\hline Variable & Variable classes & Frequency & Percent \\
\hline \multirow{3}{*}{$\begin{array}{l}\text { Taking drug for } \\
\text { hypertension }\end{array}$} & Yes & 166 & 79.8 \\
\hline & No & 42 & 20.2 \\
\hline & Total & 208 & 100.0 \\
\hline \multirow{12}{*}{ Drugs } & Amlodipine & 22 & 13.3 \\
\hline & Atenolol & 25 & 15.1 \\
\hline & Atenolol, Amlodipine & 3 & 1.8 \\
\hline & Bisoprolol fumarate & 57 & 34.3 \\
\hline & Candesartan, Indapamide & 5 & 3.0 \\
\hline & Candesartan & 9 & 5.4 \\
\hline & Enalapil maleate, Bisopolol & 5 & 3.0 \\
\hline & Enalapil maleate & 17 & 10.2 \\
\hline & Furosemide & 6 & 3.6 \\
\hline & Valsatran & 8 & 4.8 \\
\hline & Valsatran, Hydrochlorothizide & 9 & 5.4 \\
\hline & Total & 166 & 100.0 \\
\hline
\end{tabular}

Table 9: Percentage Distribution of Study Sample Population by taking herbs for hypertension.

\begin{tabular}{ccc}
\hline Taking herbs for hypertension & Frequency & Percent \\
\hline Yes & 107 & 51.4 \\
No & 101 & 48.6 \\
Total & 208 & 100.0 \\
\hline
\end{tabular}


Table 10: Percentage Distribution of Study Sample Population by herbal medicine taking.

\begin{tabular}{|c|c|c|c|c|c|c|}
\hline \multirow{2}{*}{$\begin{array}{c}\text { Herbal Medicine } \\
\text { Taking }\end{array}$} & \multicolumn{2}{|c|}{ Yes } & \multicolumn{2}{|c|}{ No } & \multicolumn{2}{|c|}{ No Answer } \\
\hline & Frequency & Percent & Frequency & Percent & Frequency & Percent \\
\hline Garlic & 76 & 36.5 & 31 & 14.9 & 101 & 48.6 \\
\hline Cinnamon & 50 & 24.0 & 57 & 27.4 & 101 & 48.6 \\
\hline Hibiscus sabdariffa & 55 & 26.4 & 52 & 25.0 & 101 & 48.6 \\
\hline Flax seed & 11 & 5.3 & 96 & 46.2 & 101 & 48.6 \\
\hline Other & 4 & 1.9 & 103 & 49.5 & 101 & 48.6 \\
\hline
\end{tabular}

hibiscus sabdariffa with (26.4\%). In the third class came cinnamon with (24.0\%). At fourth class came flaxseed by (5.3\%).

It is clear from the data in Table (11) that the majority of the sample takes herbal medicine daily and by $(22.1 \%)$. Then came the proportion of those who take it sometimes (15.9\%), but the proportion of those who take it Often (13.5\%).

Table (12) shows the health benefits of blood pressure for herbal medicinal products. It is noted that $(44.2 \%)$ of the study subjects indicated that they received positive benefits. The percentage of those who did not receive health benefits (28.8\%).

Note from Table (13) data that only (8.7\%) know medicinal herbs and verify that they are safe with high blood pressure medicines. The larger proportion $(42.8 \%)$ does not do that.

It is noted from the data in Table (14) that the highest proportion of the study members take herbal tea as a treatment (48.1\%). But only (3.4\%) of the subjects did not take herbal tea as a treatment.

Table (15) shows the side effects of medicinal herbs, noting that (19.2\%) did not experience any side effects. The most common side effects were gastrointestinal symptoms (15.4\%). In the second level, headache was (10.1\%).

Table (16) shows the figure taken by medicinal herbs. It is noted that the majority of those who take medicinal herbs in the form of Liquid with (48.1\%) percent. And a simple proportion of those who take it in the form of powder (3.4\%).

Table (17) shows that the proportion of people receiving dietary supplements for hypertension is only (10.1\%). But highest percentage (40.4\%) does not take supplements as a treatment for high blood pressure.

The data in Table (18), show that the highest percentage of study subjects ate omega-3 fatty acids with (5.8\%), followed by cod liver oil (1.0\%). The data also show that (3.4\%) take other supplements.

Table (19), shows that individuals who take food supplements often (7.7\%), and in the second class they sometimes eat (2.4\%).

Table (20) shows the side effects of dietary supplements. The most common side effects were Anorexia (3.8\%), and Headache and symptoms (3.4\%) respectively. While the percentage of those who did not suffer side effects $(2.9 \%)$.

Table (21) shows that there is four groups:

- Group 1: hypertensive patients taking drug only, the SBP mean for this group (122.55) and the DBP mean (75.25) which means that the hypertensive patients which takes the drug alone have a significant effect on the SBP and DBP.

- Group 2: hypertensive patients taking herbs \&lor supplements only, the SBP mean for this group (144.29) and the DBP (81.79) which means that the hypertensive patients takes the herbs \&lor supplements alone have no significant effect on the SBP and DBP.

- Group 3: hypertensive patients taking drug and herbs and supplements, the SBP mean for this group (115.17) and the DBP
(68.58) which means that the hypertensive patients takes the drug and herbs and supplements have a significant effect on the SBP and DBP.

- Group 4: hypertensive patients taking drug and herbs, the SBP mean for this group (125.90) and the DBP (67.60) which means that the hypertensive patients takes the drug and herbs have a significant effect on the SBP and DBP.

Table (22):

1. There was a significant difference $(\mathrm{P}$-value $=0.0001)$ between Mean systolic blood pressure SPB of patients taking only antihypertensive drug (Group 1) and Mean SPB of patients taking only herbs \&lor supplement (Group 2).That means that the drugs were more potent than the herbs \&lor supplement.

2. There was a significant difference $(\mathrm{P}$-value $=0.0290)$ between Mean SPB of (Group 1) and Mean SPB of patients taking drug and herbs (Group 4).That means that the drugs were more potent and the herbs have no effect on the SBP.

3. There was a significant difference $(P$-value $=0.0050)$ between Mean SPB of (Group 1) and Mean SPB of patients taking drug and herbs and supplements (Group 3).That means that the combination of drugs and hers and supplement were more potent than taking the drug only.

Table (23):

1. There was a significant difference (P-value $=0.0001)$ between Mean diastolic blood pressure DPB of (Group 1) and Mean DPB (Group 2).That means that the drugs is more potent than the herbs \&lor supplement.

2. There was a significant difference $(P$-value $=0.0001)$ between $D P B$ Mean (75.25) of (Group 1) and DPB Mean (67.60) of (Group 4).That means that the combination of drugs and herbs were more potent than taking the drug only.

3. There was a significant difference $(\mathrm{P}$-value $=0.0001)$ between $\mathrm{DPB}$ Mean(75.25) of (Group 1) and DPB Mean (68.58) of (Group 3).That means that the combination of drugs and herbs and supplement were more potent than taking the drug only.

From table 24, it is evident that the use of the different types of herbs in treatment of hypertension had different level of significance. There was a significant effect $(p=0.011)$ between the taking of garlic herbs which had SBP mean of 133.49 and not taking the given herb which had SBP mean 127.02. This means that taking garlic has no effect on systolic blood pressure. On the other hand, the use of Cinnamon had a significant effect $(p=0.0001)$ between the usage of Cinnamon and not using Cinnamon, with SBP mean of 127.55 for taking and SBP mean of 135.18 for not taking This means that it was more potent to take Cinnamon than not using it. Similarly, the use of Hibiscus sabdariffa had no significant effect $(\mathrm{p}=0.000)$ between the usage of the given herb and not using it, with SBP mean of 137.14 for taking and SBP mean of 125.77 for not taking. This gave an implication it was not more potent to use hibiscus herb in treatment of hypertension. Lastly, the use of Flax 
Table 11: Percentage Distribution of Study Sample Population by frequently have used the herbs over the last 12 months.

\begin{tabular}{ccc}
\hline Frequently have used the herbs over 12 month & Frequency & Percent \\
\hline Daily & 46 & 22.1 \\
Often & 28 & 13.5 \\
Sometime & 33 & 15.9 \\
never & 101 & 48.6 \\
Total & 208 & 100.0 \\
\hline
\end{tabular}

Table 12: Percentage Distribution of Study Sample Population by think herbal Products has health benefits in relation to your blood pressure.

\begin{tabular}{ccc}
\hline $\begin{array}{c}\text { Think herbal Products has health benefits in } \\
\text { relation to your blood pressure }\end{array}$ & Frequency & Percent \\
\hline Yes & 92 & 44.2 \\
No & 60 & 28.8 \\
No answer & 56 & 26.9 \\
Total & 208 & 100.0 \\
\hline
\end{tabular}

Table 13: Percentage Distribution of Study Sample Population by know about the herbs you are using and check if it's safe with your hypertension medication.

\begin{tabular}{ccc}
\hline $\begin{array}{l}\text { Know about the herbs you are using and check if } \\
\text { it's safe with your hypertension medication }\end{array}$ & Frequency & Percent \\
\hline Yes & 18 & 8.7 \\
No & 89 & 42.8 \\
No answer & 101 & 48.6 \\
Total & 208 & 100.0 \\
\hline
\end{tabular}

Table 14: Percentage Distribution of Study Sample Population by drink herbal teas as medicine.

\begin{tabular}{ccc}
\hline Drink herbal teas as medicine & Frequency & Percent \\
\hline Yes & 100 & 48.1 \\
No & 7 & 3.4 \\
No answer & 101 & 48.6 \\
Total & 208 & 100.0 \\
\hline
\end{tabular}

Table 15: Percentage Distribution of Study Sample Population by experience any side effect due to herbal medicine.

\begin{tabular}{|c|c|c|c|c|c|c|}
\hline \multirow{2}{*}{$\begin{array}{l}\text { Experience any side effect due to } \\
\text { herbal medicine }\end{array}$} & \multicolumn{2}{|c|}{ Yes } & \multicolumn{2}{|c|}{ No } & \multicolumn{2}{|c|}{ No answer } \\
\hline & Frequency & Percent & Frequency & Percent & Frequency & Percent \\
\hline nausea & 11 & 5.3 & 96 & 46.2 & 101 & 48.6 \\
\hline dizziness & 4 & 1.9 & 103 & 49.5 & 101 & 48.6 \\
\hline headache & 21 & 10.1 & 86 & 41.3 & 101 & 48.6 \\
\hline gastrointestinal & 0 & 0.0 & 107 & 51.4 & 101 & 48.6 \\
\hline symptoms & 32 & 15.4 & 75 & 36.1 & 101 & 48.6 \\
\hline skin rash & 2 & 1.0 & 105 & 50.5 & 101 & 48.6 \\
\hline dry mouth & 10 & 4.8 & 97 & 46.6 & 101 & 48.6 \\
\hline anorexia & 6 & 2.9 & 101 & 48.6 & 101 & 48.6 \\
\hline bleeding disorder & 0 & 0.0 & 107 & 51.4 & 101 & 48.6 \\
\hline no side effect & 40 & 19.2 & 67 & 32.2 & 101 & 48.6 \\
\hline other & 4 & 1.9 & 103 & 49.5 & 101 & 48.6 \\
\hline
\end{tabular}

Table 16: Percentage Distribution of Study Sample Population by the form of herbal taking.

\begin{tabular}{ccc}
\hline Form of Herbal Taking & Frequency & Percent \\
\hline Liquid & 100 & 48.1 \\
powder & 7 & 3.4 \\
No answer & 101 & 48.6 \\
Total & 208 & 100.0 \\
\hline
\end{tabular}


Table 17: Percentage Distribution of Study Sample Population by taking supplements for hypertension.

\begin{tabular}{ccc}
\hline Taking supplements for hypertension & Frequency & Percent \\
\hline Yes & 21 & 10.1 \\
No & 84 & 40.4 \\
No answer & 103 & 49.5 \\
Total & 208 & 100.0 \\
\hline
\end{tabular}

Table 18: Percentage Distribution of Study Sample Population by supplements is taking.

\begin{tabular}{|c|c|c|c|c|c|c|}
\hline \multirow{2}{*}{ Supplements is taking } & \multicolumn{2}{|l|}{ Yes } & \multicolumn{2}{|l|}{ No } & \multicolumn{2}{|l|}{ No answer } \\
\hline & Frequency & Percent & Frequency & Percent & Frequency & Percent \\
\hline Magnesium & 0 & 0.0 & 21 & 10.1 & 187 & 89.9 \\
\hline calcium & 0 & 0.0 & 21 & 10.1 & 187 & 89.9 \\
\hline cod liver oil & 2 & 1.0 & 19 & 9.1 & 187 & 89.9 \\
\hline folic acid & 0 & 0.0 & 21 & 10.1 & 187 & 89.9 \\
\hline omega-3 fatty acids & 12 & 5.8 & 9 & 4.3 & 187 & 89.9 \\
\hline other & 7 & 3.4 & 14 & 6.7 & 187 & 89.9 \\
\hline
\end{tabular}

Table 19: Percentage Distribution of Study Sample Population by frequently have used the supplements over the last 12 months.

\begin{tabular}{ccc}
\hline Frequently have used the supplements over $\mathbf{1 2}$ month & Frequency & Percent \\
\hline Daily & 0 & 0.0 \\
Often & 16 & 7.7 \\
Sometime & 5 & 2.4 \\
never & 187 & 89.9 \\
Total & 208 & 100.0 \\
\hline
\end{tabular}

Table 20: Percentage Distribution of Study Sample Population by experience any side effect due to supplements.

\begin{tabular}{|c|c|c|c|c|c|c|}
\hline \multirow{2}{*}{$\begin{array}{l}\text { Experience any side effect due to } \\
\text { supplements }\end{array}$} & \multicolumn{2}{|c|}{ Yes } & \multicolumn{2}{|c|}{ No } & \multicolumn{2}{|c|}{ No answer } \\
\hline & Frequency & Percent & Frequency & Percent & Frequency & Percent \\
\hline Nausea & 0 & 0.0 & 21 & 10.1 & 187 & 89.9 \\
\hline Dizziness & 0 & 0.0 & 21 & 10.1 & 187 & 89.9 \\
\hline Headache & 7 & 3.4 & 14 & 6.7 & 187 & 89.9 \\
\hline gastrointestinal & 0 & 0.0 & 21 & 10.1 & 187 & 89.9 \\
\hline symptoms & 7 & 3.4 & 14 & 6.7 & 187 & 89.9 \\
\hline skin rash & 0 & 0.0 & 21 & 10.1 & 187 & 89.9 \\
\hline dry mouth & 0 & 0.0 & 21 & 10.1 & 187 & 89.9 \\
\hline Anorexia & 8 & 3.8 & 13 & 6.3 & 187 & 89.9 \\
\hline bleeding disorder & 0 & 0.0 & 21 & 10.1 & 187 & 89.9 \\
\hline no side effect & 6 & 2.9 & 15 & 7.2 & 187 & 89.9 \\
\hline other & 0 & 0.0 & 21 & 10.1 & 187 & 89.9 \\
\hline
\end{tabular}

Table 21: The descriptive statistics for blood pressure readings by group.

\begin{tabular}{|c|c|c|c|c|c|c|}
\hline blood pressure & Group & $\mathrm{N}$ & Mean & Std. Deviation & Minimum & Maximum \\
\hline \multirow{5}{*}{$\begin{array}{l}\text { Systolic blood } \\
\text { pressure }\end{array}$} & Drug & 101 & 122.55 & 9.83 & 107.50 & 140.00 \\
\hline & herbs and/or supplements & 42 & 144.29 & 4.76 & 137.50 & 152.50 \\
\hline & drug and herbs & 50 & 125.90 & 6.06 & 117.50 & 135.00 \\
\hline & drug \& herbs \& supplements & 15 & 115.17 & 5.04 & 110.00 & 120.00 \\
\hline & Total & 208 & 127.21 & 11.93 & 107.50 & 152.50 \\
\hline \multirow{5}{*}{$\begin{array}{l}\text { Diastolic blood } \\
\text { pressure }\end{array}$} & drug & 101 & 75.25 & 6.60 & 62.50 & 85.00 \\
\hline & herbs and/or supplements & 42 & 81.79 & 6.49 & 72.50 & 92.50 \\
\hline & drug and herbs & 50 & 67.60 & 6.59 & 58.75 & 77.50 \\
\hline & drug \& herbs \& supplements & 15 & 68.58 & 4.72 & 63.75 & 75.00 \\
\hline & Total & 208 & 74.25 & 8.14 & 58.75 & 92.50 \\
\hline
\end{tabular}


seed had a significant effect $(\mathrm{p}=0.007)$ with SBP mean of 120.45 for taking Flax seed and SBP mean of 132.89 for not taking the given seed. This means it was more potent to use the Flax seeds than not using it.

From table 25, it is evident there was a significant effect $(\mathrm{p}=0.041)$ between the taking of garlic herbs which had DBP mean of 74.47 and not taking the given herb which had DBP mean 70.44. This means not taking or using garlic was more potent than the use or taking of garlic. On the other hand, the use of Cinnamon had a significant effect $(p=0.831)$ between the usage of Cinnamon and not using Cinnamon, with DBP mean of 73.10 for taking and SBP mean of 73.49 for not taking This means implies that it was more potent to take Cinnamon than not using it. Similarly, the use of Hibiscus sabdariffa had no significant effect $(\mathrm{p}=0.142)$ between the usage of the given herb and not using it, with DBP mean of 74.59 for taking and DBP mean of 71.95 for not taking. This gave an implication it was not more potent to use hibiscus herb in treatment of hypertension. Lastly, the use of Flax seed had a significant effect $(\mathrm{p}=0.039)$ with DBP mean of 67.84 for taking Flax seed and DBP mean of 73.93 for not taking the given seed. This means it was more potent to use the given herb than not using it.

It was reported that $51.4 \%$ of the study subjects used herbal medicines as treatment for hypertension conditions as shown by table 9 . Also, the most preferred medicinal herb was the garlic with $36.5 \%$ followed with hibiscus, which had $26.4 \%$.

The study also investigated the various side effects that were associated with the use of either supplements or medicinal herbs, and it was

Table 22: T-test results for independent samples to test systolic pressure differences by groups.

\begin{tabular}{|c|c|c|c|c|c|c|c|c|}
\hline Test & Independent & Group & $\mathrm{N}$ & Mean & Standard Deviation & T-value & D.F & P-value \\
\hline \multirow[b]{2}{*}{1} & \multirow[b]{2}{*}{$\begin{array}{l}\text { Systolic blood } \\
\text { pressure }\end{array}$} & Drug & 101 & 122.55 & 9.83 & \multirow[b]{2}{*}{13.654} & \multirow[b]{2}{*}{141} & \multirow[b]{2}{*}{0.0001} \\
\hline & & $\begin{array}{l}\text { Herbs and/or } \\
\text { supplements }\end{array}$ & 42 & 144.29 & 4.76 & & & \\
\hline \multirow{2}{*}{2} & \multirow{2}{*}{$\begin{array}{l}\text { Systolic blood } \\
\text { pressure }\end{array}$} & Drug & 101 & 122.55 & 9.83 & \multirow{2}{*}{2.209} & \multirow{2}{*}{149} & \multirow{2}{*}{0.0290} \\
\hline & & Drug and herbs & 50 & 125.90 & 6.06 & & & \\
\hline \multirow[b]{2}{*}{3} & \multirow{2}{*}{$\begin{array}{l}\text { Systolic blood } \\
\text { pressure }\end{array}$} & Drug & 101 & 122.55 & 9.83 & \multirow[b]{2}{*}{2.845} & \multirow[b]{2}{*}{114} & \multirow[b]{2}{*}{0.0050} \\
\hline & & $\begin{array}{l}\text { Drug \& herbs \& } \\
\text { supplements }\end{array}$ & 15 & 115.17 & 5.04 & & & \\
\hline
\end{tabular}

Table 23: T-test results for independent samples to test Diastolic pressure differences by groups.

\begin{tabular}{|c|c|c|c|c|c|c|c|c|}
\hline Test & Independent & Group & $\mathrm{N}$ & Mean & Standard Deviation & T-value & D.F & P-value \\
\hline \multirow[b]{2}{*}{1} & \multirow[b]{2}{*}{$\begin{array}{l}\text { Diastolic blood } \\
\text { pressure }\end{array}$} & Drug & 101 & 75.25 & 6.60 & \multirow[b]{2}{*}{5.421} & \multirow[b]{2}{*}{141} & \multirow[b]{2}{*}{0.0001} \\
\hline & & $\begin{array}{l}\text { Herbs and/or } \\
\text { supplements }\end{array}$ & 42 & 81.79 & 6.49 & & & \\
\hline \multirow{2}{*}{2} & \multirow{2}{*}{$\begin{array}{l}\text { Diastolic blood } \\
\text { pressure }\end{array}$} & Drug & 101 & 75.25 & 6.60 & \multirow{2}{*}{6.730} & \multirow{2}{*}{149} & \multirow{2}{*}{0.0001} \\
\hline & & Drug and herbs & 50 & 67.60 & 6.59 & & & \\
\hline \multirow[b]{2}{*}{3} & \multirow{2}{*}{$\begin{array}{l}\text { Diastolic blood } \\
\text { pressure }\end{array}$} & Drug & 101 & 75.25 & 6.60 & \multirow[b]{2}{*}{3.764} & \multirow[b]{2}{*}{114} & \multirow[b]{2}{*}{0.0001} \\
\hline & & $\begin{array}{l}\text { Drug \& herbs \& } \\
\text { supplements }\end{array}$ & 15 & 68.58 & 4.72 & & & \\
\hline
\end{tabular}

Table 24: T-test results for independent samples to test systolic pressure differences by taking kind of herbs.

\begin{tabular}{|c|c|c|c|c|c|c|c|c|}
\hline Test & \multicolumn{2}{|c|}{ Herbs } & $\mathrm{N}$ & Mean & Standard Deviation & T-value & D.F & P-value \\
\hline \multirow{2}{*}{1} & \multirow{2}{*}{ Garlic } & Yes & 76 & 133.49 & 11.14 & \multirow{2}{*}{2.575} & \multirow{2}{*}{105} & \multirow{2}{*}{0.011} \\
\hline & & No & 31 & 127.02 & 13.27 & & & \\
\hline \multirow{2}{*}{2} & \multirow{2}{*}{ Cinnamon } & Yes & 50 & 127.55 & 10.28 & \multirow{2}{*}{3.412} & \multirow{2}{*}{105} & \multirow{2}{*}{0.001} \\
\hline & & No & 57 & 135.18 & 12.52 & & & \\
\hline \multirow{2}{*}{3} & \multirow{2}{*}{ Hibiscus sabdariffa } & Yes & 55 & 137.14 & 9.20 & \multirow{2}{*}{5.483} & \multirow{2}{*}{105} & \multirow{2}{*}{0.000} \\
\hline & & No & 52 & 125.77 & 12.12 & & & \\
\hline \multirow{2}{*}{4} & \multirow{2}{*}{ Flax seed } & Yes & 11 & 120.45 & 14.53 & \multirow{2}{*}{3.385} & \multirow{2}{*}{105} & \multirow{2}{*}{0.001} \\
\hline & & No & 96 & 132.89 & 11.18 & & & \\
\hline \multirow{2}{*}{5} & \multirow{2}{*}{ Other } & Yes & 4 & 147.50 & 0.00 & \multirow{2}{*}{2.759} & \multirow{2}{*}{105} & \multirow{2}{*}{0.007} \\
\hline & & No & 103 & 131.0 & 11.91 & & & \\
\hline
\end{tabular}

Table 25: T-test results for independent samples to test Diastolic pressure differences by taking kind of herbs.

\begin{tabular}{|c|c|c|c|c|c|c|c|c|}
\hline Test & \multicolumn{2}{|c|}{ Herbs } & $\mathbf{N}$ & Mean & Standard Deviation & T-value & D.F & P-value \\
\hline \multirow{2}{*}{1} & \multirow{2}{*}{ Garlic } & Yes & 76 & 74.47 & 10.23 & \multirow{2}{*}{2.066} & \multirow{2}{*}{105} & \multirow{2}{*}{0.041} \\
\hline & & No & 31 & 70.44 & 5.62 & & & \\
\hline \multirow{2}{*}{2} & \multirow{2}{*}{ Cinnamon } & Yes & 50 & 73.10 & 8.09 & \multirow{2}{*}{0.214} & \multirow{2}{*}{105} & \multirow{2}{*}{0.831} \\
\hline & & No & 57 & 73.49 & 10.30 & & & \\
\hline \multirow{2}{*}{3} & \multirow{2}{*}{$\begin{array}{l}\text { Hibiscus } \\
\text { sabdariffa }\end{array}$} & Yes & 55 & 74.59 & 11.04 & \multirow{2}{*}{1.479} & \multirow{2}{*}{105} & \multirow{2}{*}{0.142} \\
\hline & & No & 52 & 71.95 & 6.83 & & & \\
\hline 4 & Flax seed & No & 96 & 73.93 & 9.43 & 2.092 & 105 & 0.039 \\
\hline \multirow{2}{*}{5} & \multirow{2}{*}{ Other } & Yes & 4 & 85.00 & 0.00 & \multirow{2}{*}{2.636} & \multirow{2}{*}{105} & \multirow{2}{*}{0.010} \\
\hline & & No & 103 & 72.85 & 9.17 & & & \\
\hline
\end{tabular}


noted that the most common symptoms of the side effects experienced were nausea, headache, and dizziness, skin rash, bleeding disorder, gastrointestinal symptoms, and anorexia. The study reported that gastrointestinal symptoms were the most common side effects that the sample patients experienced when using medicinal herbs with $15.4 \%$ while a headache was second with $10.1 \%$ as shown in table 16 . There was a significant difference $(\mathrm{P}$-value $=0.0001)$ regarding the patients who took only antihypertensive drugs and the mean of the SPB of the patients who took only herbs or the supplements thus indicating that the drugs seemed more potent than the herbs in conjunction with the supplements. There was a significant effect $(\mathrm{P}$-value $=0.0001)$ between DPB Mean (75.25) of (Group 1) and DPB Mean (67.60) of (Group 4) thus indicating that the combination of drugs and herbs was more potent than taking the drug only, as shown in table 22.

\section{DISCUSSION}

The study was instrumental in identifying the prevalence of medicinal use $(51.4 \%)$ among hypertensive patients in Jordan. The prevalence of the use of medicinal herbs for the treatment of hypertension in Iraq was reported to be (65.5\%) while that of Saudi Arabia has been reported to be $63.8 \%{ }^{5}$ The high prevalence of the usage of medicinal herbs has been attributed to the Islamic culture and beliefs regarding the consumption of herbs as treatment for various health conditions. Some previous evidence in the Middle East has reported some high rate of medicinal herbs use in hypertensive patients. Other studies conducted in developed nations have also shown some substantive increase in the application of medicinal herbs among the different hypertensive patients. ${ }^{5}$ In the study conducted, the use of medicinal herbs was related to the marital status, educational level and the hypertension duration. On the other hand, the usage was not associated with the age, gender and the comorbidity presence. There has existed some inadequate and conflicting information regarding the alternative medicines for hypertension that can be accessed by various patients.

A study undertaken in Tanzania reported that the patients from poor socioeconomic backgrounds, those with poor or inadequate knowledge concerning hypertension had some high prevalence of using medicinal herbs for their treatment. ${ }^{18}$ Additionally, the studies conducted in China and Iraq confirmed the association of marital status, educational level, and socioeconomic level as some of the critical factors that influence the use and intake of medicinal herbs for treatment by hypertensive patients. ${ }^{6}$ Some other studies have also indicated that use of medicinal herbs for hypertension was not dependent on the socioeconomic and demographic factors as determined in our study. The given variation in the findings may be attributed to various cultural differences, variations in beliefs and norms of the communities that took part in the different studies. From the given variations, it may be deduced that the impact of the socioeconomic and demographic factors may be dependent on the community or country of study. The study also identified various factors such as body weight, medical conditions, and family history, smoking status and diet and lifestyle changes as the main risk factors for hypertension. ${ }^{10,11}$

The study investigated the prevalence of the use of medicinal herbs and other drugs or supplements in the treatment of hypertension, from table 9 , it is evident the majority of the sample (51.4\%) use medicinal herbs for the treatment of different kinds of hypertension. The use of medicinal herbs is backed with the availability of a similar trend in the other developing and developed nations such as China, Iraq and Tanzania. The high prevalence of the use of medicinal herbs in Jordan was boosted by various factors such as the friendly culture towards its use, low cost of the medicinal herbs and the availability of the different medicinal herbs in the market. ${ }^{7}$ However, the use of the medicinal herbs also had some health complications inform of the side effects that were experienced by the sample patients who used the given medicine for the treatment of hypertension as shown in table 16. The study indicated that the majority of the patients experienced side effects with only $19.2 \%$ not experiencing the side effects. The most common side effects experienced were gastrointestinal symptoms with $15.4 \%$ while a headache was second with $10.1 \%$ as shown in table 16 . The existence of side effects could worsen the clinical conditions and may have a significant impact on the different treatments prescribed by medical practitioners. The usage of garlic herbs was the most common among the medicinal herbs, with $36.5 \%$ while hibiscus sabdariffa had $26.4 \%$. The practice of medicinal herbs forms an important aspect of Islamic culture and traditions hence it is mainly recommended as one of the vital treatment options for a variety of health conditions. ${ }^{8}$

The use of supplements and other types of treatment for hypertension had some lower percentages as compared to the use of medicinal herbs. This may be attributed to the fact that western or scientific practices still being uncommon among Arabic culture and beliefs. It can be concluded from the study that the characteristics of the patients such as the education level, marital status and the socioeconomic factors were the influential factors for most patients in choosing the use of medicinal herbs. ${ }^{9}$ However, it may not be easier to have a conclusive theory to describe the choice of the medicinal herbs as compared to other forms of treatment due to various contradictory findings of different studies in different communities and countries.

There still exists inadequate or minimal reasons behind why patients in Jordan and other cultures have the preference for medicinal herbs in the treatment of the different hypertension diseases. The patients that participated in this study used medicinal herbs in supporting the standard treatment, protection of their health, adherence to the Arabic culture and the obtaining of good treatment at some low cost. ${ }^{10}$ The highlighted reasons were in tandem with those of the previous studies that were conducted on the same topic. The usage of the medicinal herbs for hypertensive treatment in this study was mainly supported by advice and information gathered from the internet, family or relatives, CAM users, friends or colleagues, books or magazines and the doctor or qualified pharmacists as shown in table 21. The influence of family or relatives was the highest with $40.9 \%$. On the other hand, the influence of Cam user was the second with $17.8 \%$ while the internet was the third with $17.3 \%$. It is worth noting that the CAM users also did not seek proper and professional advice from the doctors since they mostly relied on the family or relatives and the internet on making their decisions whether to use supplements or not 23 . The mean expenditure per annum for the sample patients included in the study was 20.95 dinars. However, there is scanty information regarding the total global expenditure on the use of CAM.

The study included patient perceptions concerning the side effects of the various forms of hypertension treatment. The most common symptoms of side effects were nausea, headache, and dizziness, skin rash, bleeding disorder, gastrointestinal symptoms and anorexia. Despite the scanty side effects of the use of medicinal herbs, the study reported that gastrointestinal symptoms were the most common side effects that the sample patients experienced as shown in table $16 .{ }^{11-13}$ The experience of a headache as the side effect was the second most common among the patients who used herbal medicine.

From table 28, 29 it can be deduced that the use of drugs, herbs and the supplements was more potent than taking drugs only for the treatment of hypertension as shown by the existence of the significance difference ( $p$ value $=0.0050$ ). The more effective of the use of the drugs, herbs and other supplements can be attributed to the lesser side effects of the medicinal herbs as compared to the contemporary drugs. Supplements also play a pivotal role in increasing the effectiveness since supplements such as omega-3 fatty acids and magnesium have proven to be important in reducing depression and hypertension. ${ }^{14,15}$ This more potency of 
the use of drugs, herbs and supplements can also be attributed to the existence of the significance effect on the SBP and DBP as shown in table 27. The study also highlighted the use of various supplements in the treatment of hypertension. Magnesium, cod liver oil, calcium, folic acid and omega -3 fatty acids were the main supplements that were used. The debate on the effectiveness of the medicinal herbs in the treatment of hypertension is still open since there is still more evidence needed in conclusively supporting the research.

\section{CONCLUSION}

From the study, it can be deduced that the use of herbal medicines and supplements as well as antihypertensive drugs was prevalent among hypertensive patients in Jordan. Over half of the patients involved in this study were taking medicinal herbs to treat their blood pressure diseases. Adults from low socioeconomic status, those with misunderstandings about hypertension, and those without high educational level were more likely to take herbs.

In a worrying trend, however, only $8.7 \%$ of the patients involved in this study know whether the herbs they were using was safe for their condition. The data obtained during the study shows that both herbal medicine and supplements do not affect the blood pressure while antihypertensive drugs are effective for hypertension patients.

In conclusion, it found that the use of the medication in controlling pressure in patients with high blood pressure is essential that does not accept change or switch, and the use of herbs and supplements is only as a complementary treatment.

It can also be deduced that a combined usage of herbal medicine and supplements with antihypertensive drugs was far more potent than using antihypertensive drugs only. It is recommended that a thorough sensitization campaign should be carried out to reduce the number of patients resorting to taking herbal medicines without any knowledge on whether the herbs are helping their conditions or not.

\section{CONFLICTS OF INTEREST}

There are no conflicts of interest.

\section{REFERENCES}

1. Engler, M.M. (2017). Role of Dietary Omega-3 Fatty Acids in Hypertension. Ann Nurs Pract, 4(1), 10-77.
2. WHO, day (2013) 'A global brief on Hyper tension World Health Day 2013'.

3. George L. Bakris, MD, Professor of Medicine (2018). Overview of Hypertension.

4. Olszanecka, A., Stopa, M., Lobacz, M., Rutkowska, K., Niemczyk, M., Radko, A. \& Czarnecka, D. (2018). Prevalence of dietary supplements and over the counter drug use in patients with arterial hypertension. Jagiellonian University Medical College.

5. Hamdan, I. I., \& Afifi, F. U. (2004). Studies on the in vitro and in vivo hypoglycemic activities of some medicinal plants used in treatment of diabetes in Jordanian traditional medicine. Journal of ethnopharmacology, 93(1), 117-121.

6. Alzweiri, M., Al Sarhan, A., Mansi, K., Hudaib, M., \& Aburjai, T. (2011) Ethnopharmacological survey of medicinal herbs in Jordan, the Northern Badia region. Journal of Ethnopharmacology, 137(1), 27-35.

7. Abu-Irmaileh, B. E., \& Afifi, F. U. (2003). Herbal medicine in Jordan with special emphasis on commonly used herbs. Journal of Ethnopharmacology, 89(2-3), 193-197.

8. Al-Qura'n, S. (2009). Ethnopharmacological survey of wild medicinal plants in Showbak, Jordan. Journal of Ethnopharmacology, 123(1), 45-50.

9. Talib, W. H., \& Mahasneh, A. M. (2010). Antiproliferative activity of plant extracts used against cancer in traditional medicine. Scientia pharmaceutica, 78(1), 33.

10. Aburjai, T., Hudaib, M., Tayyem, R., Yousef, M., \& Qishawi, M. (2007) Ethnopharmacological survey of medicinal herbs in Jordan, the Ajloun Heights region. Journal of Ethnopharmacology, 110(2), 294-304.

11. Afifi, F. U., Wazaify, M., Jabr, M., \& Treish, E. (2010). The use of herbal preparations as complementary and alternative medicine (CAM) in a sample of patients with cancer in Jordan. Complementary therapies in clinical practice, 16(4), 208-212

12. Wazaify, M., Afifi, F. U., El-Khateeb, M., \& Ajlouni, K. (2011). Complementary and alternative medicine use among Jordanian patients with diabetes. Complementary therapies in clinical practice, 17(2), 71-75.

13. Agbabiaka, T.B., Spencer, N.H., Khanom, S. and Goodman, C. (2018). Prevalence of drug-herb and drug-supplement interactions in older adults: a crosssectional survey. British Journal of General Practice, 3(7), 12-34.

14. Akansel, N., Özdemir, A., Yıldız, H., Baran, A., Dirik, M. (2017). The use of complementary and alternative medicine among hypertensive Patients. Rostrum of Asclepius, 16(3), 34-56.

15. Cormick, G., Ciapponi, A., Cafferata, M.L., \& Belizán, J.M. (2015). Calcium supplementation for prevention of primary Hypertension. JohnWiley \& Sons, Ltd.

16. Ibrahima, I.R., Hassalia, M.A., Saleemb, F., Haydar, F., Tukmagic, A. and Dawoodd, O.A. (2018). Use of complementary and alternative medicines: a cross-sectional study among hypertensive patients in Iraq. JPHS, 9, 59-65.

17. Kobayashi, E., Sato, Y., Umegaki, K. and Chiba, T. (2017). The Prevalence of Dietary Supplement Use among College Students: A Nationwide Survey in Japan. Nutrients, 9, 12-50.

18. Ferreri, A. J., Campo, E., Seymour, J. F., Willemze, R., Ilariucci, F., Ambrosetti, A., ... \& Geerts, M. L. (2004). Intravascular lymphoma: clinical presentation, natural history, management and prognostic factors in a series of 38 cases, with special emphasis on the 'cutaneous variant'1. British journal of haematology, 127(2), 173-183. 


\section{GRAPHICAL ABSTRACT}

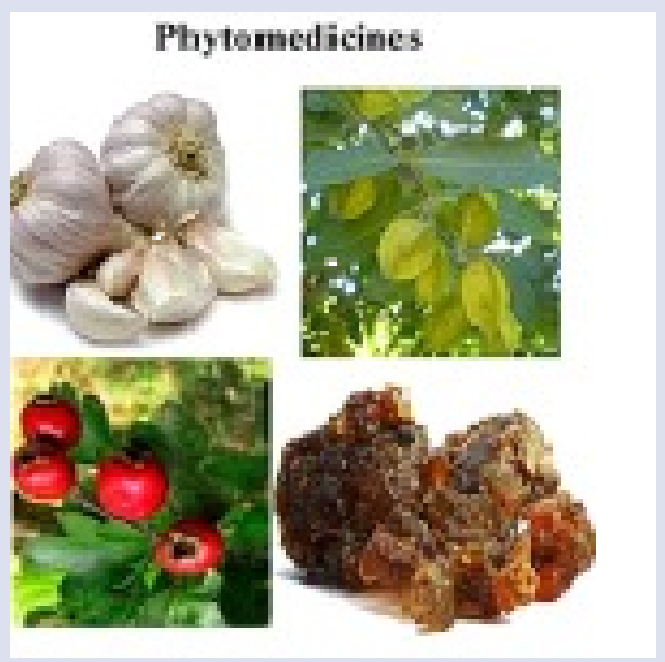

\section{ABOUT AUTHORS}

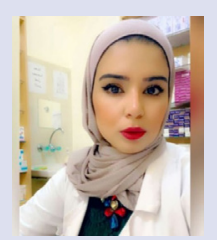

\section{Dua Al-Hadid}

Ministry of Health, Amman, JORDAN.

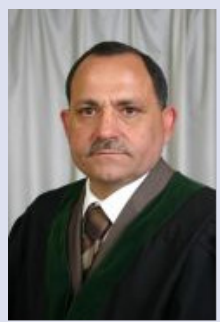

\section{Raad Jaber Musa}

Professor of Pathology, Faculty of Pharmacy, Isra University, PO Box 22 and 23, Amman, JORDAN.

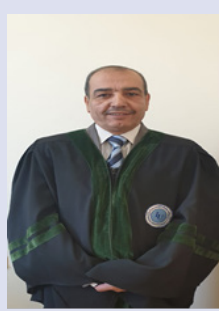

\section{Ahmad Al-Talhuni}

Assitant Professor, Faculty of Pharmacy, Isra University, PO Box 22 and 23, Amman, JORDAN.

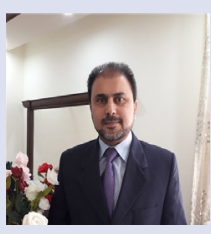

\section{Jamal Alyoussef Alkrad}

Associate Professor, Faculty of Pharmacy, Isra University, PO Box 22 and 23, Amman, JORDAN.

Cite this article: Al-Hadid D, Musa RJ, Al-Talhuni A, Alkrad JA. Prevalence of Traditional Herbs and Supplements Use Among Hypertensive Patients in Om Elamad Health Center. Pharmacogn J. 2020;12(6)Suppl:1612-22. 